\title{
Resorption of sequestrated lumbar disc herniation with conventional therapy
}

\author{
Sekestre lomber disk hernisinin konvansiyonel tedavi ile rezorpsiyonu \\ Hamide Özge Çizmeci, Merve Soysal, Birkan Sonel Tur \\ Deparment of Physical Medicine and Rehabilitation, Medical Faculty of Ankara University, Ankara, Turkey \\ Received / Geliş tarihi: January 2017 Accepted / Kabul tarihi: February 2017
}

We read with interest, the article titled "Resorption of extruded intervertebral disc herniation: Effect of physical therapy modalities" by Agirman et al. ${ }^{[1]}$ published in The Turkish Journal of Physical Medicine and Rehabilitation, Volume 62, Issue 3 . We would like to share our experiences on a similar case.

A 76-year-old man presented with a three-week history of lower back and right leg pain, loss of strength in his right leg, and urinary and fecal incontinence. He was first admitted to emergency service in March 2016. Magnetic resonance imaging (MRI) was performed which revealed L4-L5 disc sequestration with superior migration and an L4 root compression (Figure 1). Surgery was proposed; however, he refused surgery. Therefore, he was referred to our clinic in April 2016. His medical history showed that the pain increased with movement and decreased with rest. Upon his physical examination; the straight leg raise was positive at 50 degrees on the right side. The strength of the right hip flexor was $3 / 5$, the knee flexor $4 / 5$, the knee extensor $2 / 5$, and the big toe dorsiflexor 4/5. He had L4 and L5 dermatomal paresthesia on the right side, and the reflexes in his right patella and Achilles tendon were unable to be elicited. A six-week period physical therapy and rehabilitation program consisting of hotpack (20 sessions), pulsed ultrasound (20 sessions), transcutaneous electrical nerve stimulation (14 sessions), diadynamic current (14 sessions), and therapeutic electrical stimulation (28 sessions) was applied. After the fourth week of the program, we also added walking training, as he could tolerate. Initially, his urinary and fecal incontinence recovered. The pain gradually decreased. At the end of the therapy, the strength of the right hip flexor and knee extensor was 4/5, distally 5/5. In May 2016, repeated MRI showed resorption of the sequestrated disc (Figure 2). As a result, his symptoms and MRI findings regressed within two months with physical therapy and exercise program.

Cases with spontaneous regression of lumbar disc herniation (LDH) have been previously reported in the literature. There are three hypotheses: (i) dehydration, (ii) retraction of the herniated disc into the intervertebral disc space, and (iii) disc herniation into the epidural space exciting an inflammation and neovascularization which brings about enzymatic degradation and phagocytosis. ${ }^{[2]}$ Ultrastructural and
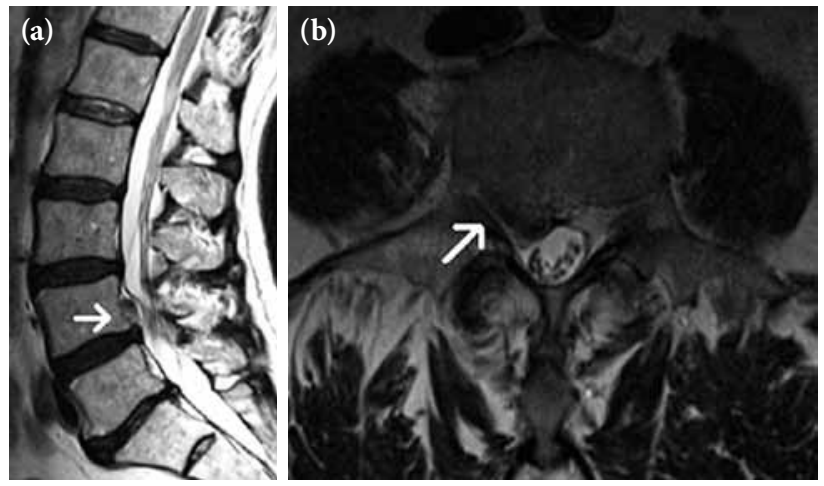

Figure 1. $\mathrm{T}_{2}$-weighted magnetic resonance imaging of the lumbar spine showing an L4-L5 disc sequestration with superior migration on the sagittal plane (a) and an L4 root compression on the axial plane (b). 


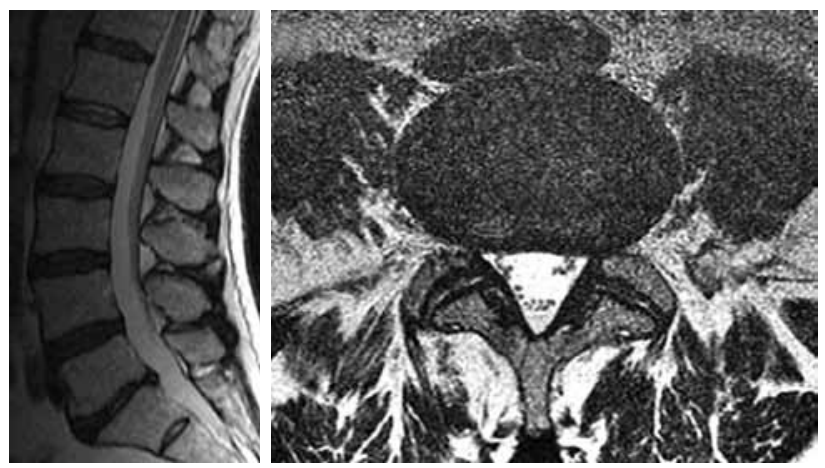

Figure 2. $\mathrm{T}_{2}$-weighted magnetic resonance imaging of the lumbar spine showing the resorption of the sequestrated disc.

immunohistochemical studies with surgical specimens support the latter hypothesis. ${ }^{[3,4]}$ Among the subtypes of LDH, sequestrations regress in the shortest time frame on average in nine months. ${ }^{[5,6]}$ In this case, the process might have been accelerated with physical therapy (from 9 months to 2 months). However, to the best of our knowledge, there is no comparative study using different approaches for regression of LDH in the literature. Hence, further studies are required to gain a better understanding about the benefits of physical therapy in this patient population.

\section{Declaration of conflicting interests}

The authors declared no conflicts of interest with respect to the authorship and/or publication of this article.

\section{Funding}

The authors received no financial support for the research and/or authorship of this article.

\section{REFERENCES}

1. Ağırman M, Durmuş O, Saral İ, Çakar E. Resorption of extruded intervertebral disc herniation: Effect of physical therapy modalities. Turk J Phys Med Rehab 2016;62:286-7.

2. Yang X, Zhang Q, Hao X, Guo X, Wang L. Spontaneous regression of herniated lumbar discs: Report of one illustrative case and review of the literature. Clin Neurol Neurosurg 2016;143:86-9.

3. Kobayashi S, Meir A, Kokubo Y, Uchida K, Takeno K, Miyazaki $\mathrm{T}$, et al. Ultrastructural analysis on lumbar disc herniation using surgical specimens: role of neovascularization and macrophages in hernias. Spine (Phila Pa 1976) 2009;34:655-62.

4. Tsarouhas A, Soufla G, Katonis P, Pasku D, Vakis A, Spandidos DA. Transcript levels of major MMPs and ADAMTS-4 in relation to the clinicopathological profile of patients with lumbar disc herniation. Eur Spine J 2011;20:781-90.

5. Takada E, Takahashi M, Shimada K. Natural history of lumbar disc hernia with radicular leg pain: Spontaneous MRI changes of the herniated mass and correlation with clinical outcome. J Orthop Surg (Hong Kong) 2001;9:1-7.

6. Chiu CC, Chuang TY, Chang $\mathrm{KH}, \mathrm{Wu} \mathrm{CH}$, Lin PW, Hsu WY. The probability of spontaneous regression of lumbar herniated disc: a systematic review. Clin Rehabil 2015;29:184-95. 